LETTER TO JMG

\title{
Interaction between the $\alpha$-T catenin gene (VR22) and APOE in Alzheimer's disease
}

\author{
E R Martin, P G Bronson, Y-J Li, N Wall, R-H Chung, D E Schmechel, G Small, P-T Xu, J Bartlett, \\ N Schnetz-Boutaud, J L Haines, J R Gilbert, M A Pericak-Vance
}

Background: APOE is the only gene that has been consistently replicated as a risk factor for late onset Alzheimer's disease. Several recent studies have identified linkage to chromosome 10 for both risk and age of onset, suggesting that this region harbours genes that influence the development of the disease. A recent study reported association between single nucleotide polymorphisms (SNPs) in the VR22 gene (CTNNA3) on chromosome 10 and plasma levels of $\mathrm{A} \beta 42$, an endophenotype related to Alzheimer's disease.

Objective: To assess whether polymorphisms in the VR22 gene are associated with Alzheimer's disease in a large sample of Alzheimer's disease families and an independent set of unrelated cases and controls.

Results: Several SNPs showed association in either the family based or case-control analyses $(p<0.05)$. The most consistent findings were with SNP6, for which there was significant evidence of association in both the families and the unrelated cases and controls. Furthermore, there was evidence of significant interaction between APOE- 4 and two of the VR22 SNPs, with the strongest evidence of association being concentrated in individuals carrying APOE- 4 .

Conclusions: This study suggests that VR22 or a nearby gene influences susceptibility to Alzheimer's disease, and the effect is dependent on APOE status.

\footnotetext{
A
} lzheimer's disease is the most common form of dementia in the elderly, and currently affects more than four million people in the USA. Four major genes (amyloid precursor protein (APP), presenilin 1 and 2 (PS1 and PS2), and apolipoprotein E (APOE)) have been identified, but these genes collectively account for only 45$55 \%$ of the genetic aetiology in this disorder. Though mutations in APP, PS1, and PS2 cause early onset Alzheimer's disease, APOE is the only gene that has been consistently replicated as a risk factor for late onset disease. Other genes contributing to the common late onset type of disease remain to be determined.

Several studies have identified linkage to chromosome 10 for both risk of Alzheimer's disease and age of onset of the disease, often in overlapping datasets. ${ }^{1-4}$ Further, association has been reported with several candidate genes in the region in different studies, including insulin degrading enzyme (IDE), plasminogen activator urinary (PLAU), and glutathione S transferase-omega (GSTO1)..$^{5-7}$ A recent study ${ }^{8}$ reported association between single nucleotide polymorphisms (SNPs) in the VR22 gene (chromosome 10q21.3), lying in the region of linkage, and plasma amyloid $\beta$ protein (specifically A $\beta 42$ ) levels in a small set of families with Alzheimer's disease. Amyloid $\beta$ aggregates in amyloid fibrils in senile plaques found in the brains of Alzheimer patients. ${ }^{9}$
Plasma A 342 levels have been shown to be increased in individuals with Alzheimer's disease, and these levels have been used as an endophenotype in attempts to map genes contributing to the disease. ${ }^{10-12}$ The finding of association between VR22 SNPs and A $\beta 42$ levels suggests that this gene may be involved in Alzheimer's disease susceptibility. However, the previous study did not specifically test the polymorphism for association with Alzheimer's disease; therefore, a direct link between VR22 and disease risk has not been established.

The VR22 gene (also called CTNNA3) codes for the $\alpha$ catenin-like protein $(\alpha-\mathrm{T}$ catenin), which is believed to be involved in cell adhesion. To examine whether polymorphisms in the VR22 gene are associated with Alzheimer's disease, we tested for association with several SNPs identified by Ertekin-Taner et $a l^{8}$ as being the most significantly associated with A $\beta 42$ levels and additional surrounding SNPs. We tested a large sample of Alzheimer families and an independent set of unrelated cases and controls for association with Alzheimer's disease.

\section{METHODS}

\section{Study samples}

Our analysis set includes both a family sample and an independent case-control sample. The family sample, described in table 1, consists of 738 families collected by the following: the Collaborative Alzheimer Project (CAP: The Joseph and Kathleen Bryan ADRC and the Center for Human Genetics at Duke University, The Center for Human Genetics research at Vanderbilt University Medical Center, and the University of California at Los Angeles Neuro-psychiatric Institute); National Institutes of Mental Health (NIMH); and the National Cell Repository for Alzheimer's Disease at Indiana University Medical Center (IU).

The dataset contains 371 families with at least one sampled affected family member and at least one sampled unaffected family member (discordant sibling pairs) informative for association analysis. The multiplex dataset consists of 580 families informative for linkage analysis.

All affected individuals met the NINDS/ADRDA criteria for probable or definite Alzheimer's disease. ${ }^{13}$ Unaffected relatives from the CAP and NIMH sites were examined and showed no signs of dementia. Unaffected individuals from IU were classified based on self report. The mean (SD) age at onset (AAO) in affected individuals was 72.31 (9.09) years, and the mean (SD) age at examination (AAE) was 74.82

Abbreviations: $A A E$, age at examination; $A A O$, age at onset; $A P L$, association in the presence of linkage; CAP, Collaborative Alzheimer Project; HWE, Hardy-Weinberg equilibrium; IU, Indiana University Medical Center; LD, linkage disequilibrium; NIMH, National Institutes of Mental Health; PDT, pedigree disequilibrium test; SNP, single nucleotide polymorphism 
Table 1 Description of family dataset

\begin{tabular}{|c|c|c|c|c|c|c|}
\hline Family type & Total families & CAP families & NIMH families & IU families & $\begin{array}{l}\text { Discordant sibling } \\
\text { pairs }\end{array}$ & Affected relative pairs \\
\hline Multiplex (n) & 580 & 87 & 349 & 124 & 1111 & 1153 \\
\hline Singleton ( $\mathrm{n}$ ) & 158 & 78 & 3 & 29 & 161 & 0 \\
\hline
\end{tabular}

(11.75) years. A positive family history of Alzheimer's disease was reported for $82 \%$ of the families.

The case-control sample consisted of 584 unrelated Alzheimer cases ascertained through the CAP and IU and 858 unrelated controls collected through the CAP. Cases had an average AAO of 71.14 (6.66) years and controls were age matched at the time of examination, with an average AAE of 71.94 (6.29) years. The cases were predominantly sporadic, with less than $4 \%$ reporting a positive family history of Alzheimer's disease in first degree relatives. All cases met the NINDS/ ADRDA criteria for probable or definite Alzheimer's disease. ${ }^{13}$ Controls had no obvious signs of cognitive or neurological impairment when enrolled in the study, as determined by personal interview by clinical personnel at the ascertainment site. All individuals included in the family and case-control analyses were white. Written consent was obtained from all participants, in agreement with protocols approved by the institutional review board at each contributing centre.

\section{SNPs and genotyping}

We studied 11 SNPs for association with Alzheimer's disease (fig 1). These SNPs included six (SNP5-SNP9 and SNP11) that were studied previously by Ertekin-Taner et $a l^{8}$ and two (SNP4 and SNP10) selected from public databases. Intron 7 of the VR22 gene contains another gene, the leucine-rich repeat transmembrane neuronal 3 (LRRTM3) gene, which encodes a brain specific protein expressed in the hippocampus. Three of the SNPs lie in the LRRTM3 gene (SNP1-SNP3, fig 1). We extracted DNA for individuals ascertained by CAP with the Puregene system (Gentra Systems, Minneapolis, Minnesota, USA). SNPs were genotyped using the ABI 7900 Taqman $^{\circledast}$ system. ${ }^{14}$ APOE alleles (corresponding to allele combinations at SNP +3937/rs429358 and SNP +4075/rs7412) were genotyped as previously reported. ${ }^{15}$ Genotyping efficiency was greater than $90 \%$, and quality control was achieved by including two sets of 12 control samples and four sets of two standard samples on each 384 well plate. The

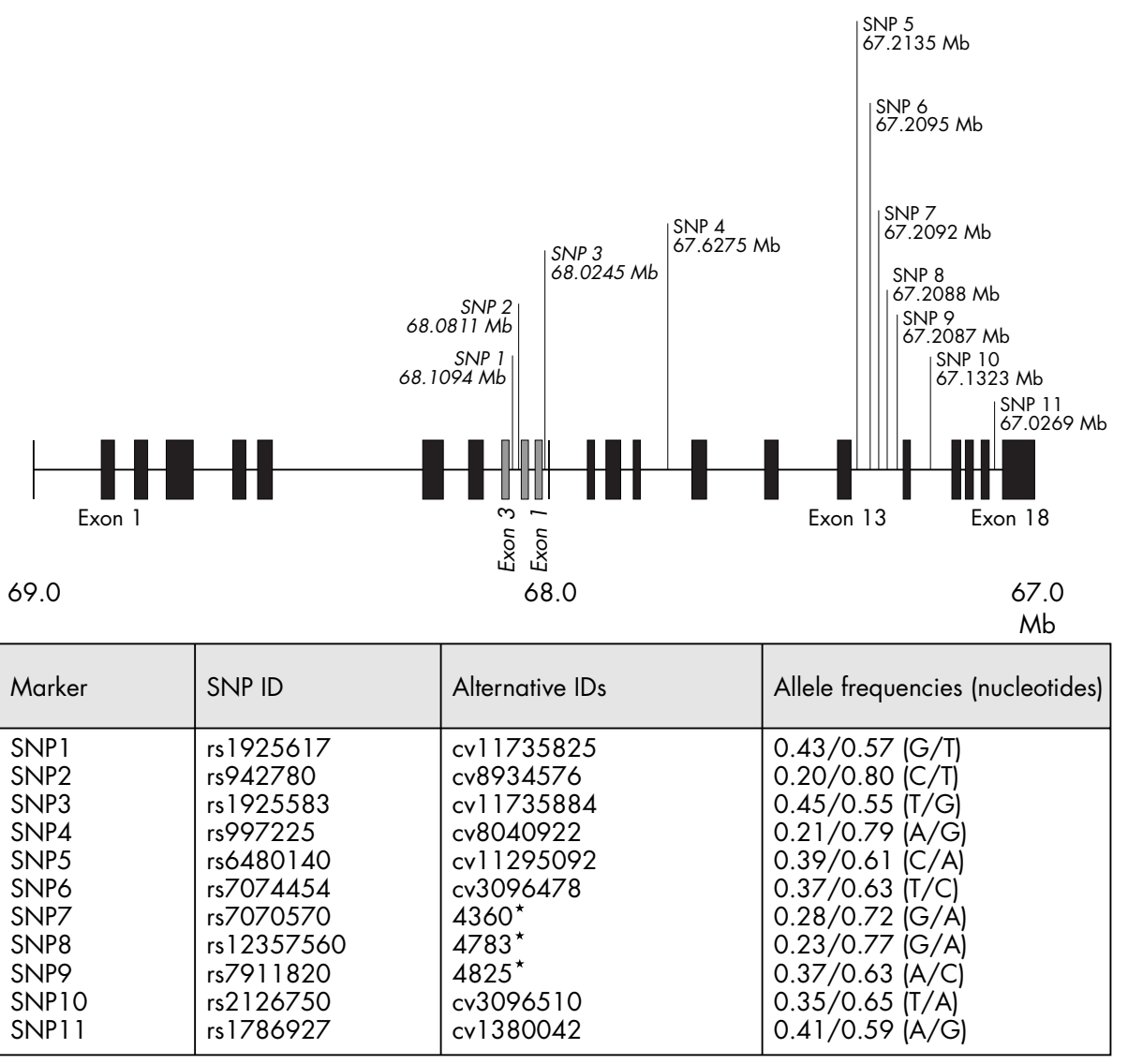

*From Ertekin-Taner et al 2003

Figure 1 SNPs analysed in VR22 and LRRTM3 genes on chromosome 10. Locations are from NCBI Build 34. VR22 exons are black and SNPs nonitalic, LRRTM3 exons are in grey, and SNPs in italics. 
laboratory was blinded to family relations, affection status, and quality control samples.

\section{Statistical analysis}

Tests for deviations from Hardy-Weinberg equilibrium (HWE) were conducted in unrelated cases, unrelated controls, and families (selecting one affected individual and one unaffected individual per family) using the exact test from the Genetic Data Analysis software. ${ }^{16}$ Measures of linkage disequilibrium (LD) were computed with GOLD. ${ }^{17}$ We report the squared correlation coefficient $\left(r^{2}\right)$ and the normalised disequilibrium coefficient $\left(D^{\prime}\right)$ between all pairs of SNPs.

Family based association analysis for Alzheimer's disease risk was conducted with the pedigree disequilibrium test (PDT) and genotype-PDT. ${ }^{18-20}$ Haplotype association analysis was conducted for pairs of markers in families using the test for association in the presence of linkage (APL). ${ }^{21}$ Haplotypes with frequencies $<0.05$ were not used in the analysis. Single point parametric linkage analysis was conducted using Fastlink $^{22}$ under affected-only dominant and recessive models. Disease allele frequencies were 0.001 and 0.20 for dominant and recessive models, respectively. Marker allele frequencies were estimated in the family dataset. We used the HOMOG program to test for linkage in the presence of heterogeneity. ${ }^{23}$ All tests were conducted in the overall sample and conditional on APOE genotype. For analysis in APOE-4 carriers, all affected individuals not carrying APOE-4 were reclassified as having an unknown phenotype. For analysis of individuals without APOE-4, all affected individuals who have an APOE-4 allele were reclassified as unknown.

Case-control analysis was conducted in the independent unrelated case-control sample using SAS $^{24}$ (SAS Institute Inc, Cary, North Carolina, USA). We carried out a logistic regression including terms for $\mathrm{AAE}$, sex, and SNP genotype. Two models were considered to dichotomise SNP genotypes: one testing carriers versus non-carriers of the major allele, denoted as $1(11+12 \vee 22)$; and the other testing carriers versus non-carriers of the minor allele, denoted as $2(22+12 \mathrm{v}$ 11). Case-control tests were conducted in the overall casecontrol sample and in the sample stratified by APOE genotype. Case-control analyses were conducted in two stages; thus sample sizes used in analyses vary for different SNPs. Initially five SNPs (SNP4-SNP7 and SNP10) were genotyped in a sample of 381 cases and 326 controls. The remaining six SNPs were genotyped later in the enlarged overall case-control dataset described above.

Tests for interaction were conducted in the unrelated casecontrol sample. We tested SNP genotypes for interaction with APOE genotypes for any SNP that was found significant in the case-control analyses described above. Logistic regression was used, adjusting for AAE and sex. We used genotype coding for the SNPs that led to significant main effects and considered carriers of APOE- $4 v$ non-carriers to code APOE genotype. We included terms for AAE, sex, SNP genotype code, APOE genotype code, and ( $\mathrm{SNP} \times \mathrm{APOE})$.

\section{RESULTS}

Hardy-Weinberg and linkage disequilibrium analyses We found no evidence for Hardy-Weinberg disequilibrium in the samples of cases, controls, or families. Pairwise LD measures are shown in table 2 for unaffected siblings (one per family). LD measures were similar in affected and unaffected individuals from families and from the unrelated case-control dataset. We found a strong correlation $\left(r^{2}\right.$ $\geqslant 0.77$ ) between alleles at SNP6 and SNP9, and between SNP7 and SNP8. All other marker pairs showed $r^{2}$ values smaller than 0.3. Values of $\mathrm{D}^{\prime}$ indicated that SNP6-SNP10 form a block with $\mathrm{D}^{\prime} \geqslant 0.87$, suggesting there has been little ancestral recombination in the region bounded by these markers. Others markers showed little evidence of LD, in particular SNP1-SNP3 in LRRTM3 showed very little LD with VR22 markers by both $r^{2}$ and $\mathrm{D}^{\prime}$ measures.

\section{Family based analyses}

Results from family based tests of association are given in table 3. The PDT gave significant results for SNP6 ( $p=0.011$, allele C positively associated) and SNP9 $(p=0.028$, allele C positively associated) in the overall sample, showing a significant association with Alzheimer's disease. The genotype-PDT (GenoPDT) showed evidence of genotype association with Alzheimer's disease for SNPl in LRRTM3 $(p=0.002)$. Examination of individual genotypes at SNP1 shows that the TT genotype is significantly more frequent in affected siblings than in unaffected siblings $(p=0.007)$.

Considering the known APOE-4 effect on Alzheimer's disease risk, we conducted a conditional PDT. In the first analysis we considered only individuals without an APOE-4 allele (107 informative families). In the second analysis, we considered only individuals who are carriers of APOE-4 (185 informative families). The results are given in table 3 . We found that significant association was restricted to the stratum of APOE-4 carriers, with SNP6 and SNP9 showing significant association consistent with results in the overall dataset.

Haplotype analysis at pairs of SNPs gave significant global test results in the overall dataset for SNP10-SNP11 $(p=0.037)$ and SNP7-SNP4 $(p=0.032)$. The result for SNP10-SNP11 increased in significance $(p=0.010)$ in individuals carrying APOE-4, and pairs containing SNP9SNP11 $(p=0.044)$ and SNP7-SNP11 $(p=0.043)$ also became significant in that subset. No global haplotype tests were significant in individuals not carrying APOE-4. Examination of individual haplotype results showed that the most significantly associated haplotype for pairs was for the A-T

Table 2 Pairwise linkage disequilibrium measures, $r^{2}$ (above diagonal) and D' (below diagonal), in unaffected individuals

\begin{tabular}{|c|c|c|c|c|c|c|c|c|c|c|c|}
\hline & SNP1 & SNP2 & SNP3 & SNP4 & SNP5 & SNP6 & SNP7 & SNP8 & SNP9 & SNP10 & SNP11 \\
\hline SNP1 & & 0.00 & 0.00 & 0.01 & 0.00 & 0.00 & 0.00 & 0.00 & 0.00 & 0.00 & 0.00 \\
\hline SNP2 & 0.10 & & 0.07 & 0.00 & 0.00 & 0.01 & 0.00 & 0.00 & 0.00 & 0.00 & 0.01 \\
\hline SNP3 & 0.05 & 0.55 & & 0.00 & 0.00 & 0.00 & 0.00 & 0.00 & 0.00 & 0.00 & 0.01 \\
\hline SNP4 & 0.12 & 0.02 & 0.11 & & 0.00 & 0.02 & 0.01 & 0.01 & 0.02 & 0.01 & 0.01 \\
\hline SNP5 & 0.01 & 0.10 & 0.02 & 0.06 & & 0.05 & 0.10 & 0.17 & 0.06 & 0.01 & 0.00 \\
\hline SNP6 & 0.01 & 0.12 & 0.01 & 0.22 & 0.24 & & 0.21 & 0.16 & 0.97 & 0.30 & 0.05 \\
\hline SNP7 & 0.09 & 0.20 & 0.03 & 0.10 & 0.67 & 0.98 & & 0.77 & 0.20 & 0.17 & 0.02 \\
\hline SNP8 & 0.01 & 0.20 & 0.01 & 0.07 & 0.97 & 0.97 & 0.98 & & 0.16 & 0.14 & 0.02 \\
\hline SNP9 & 0.00 & 0.09 & 0.04 & 0.19 & 0.25 & 0.99 & 0.97 & 0.98 & & 0.29 & 0.05 \\
\hline SNP10 & 0.07 & 0.04 & 0.07 & 0.29 & 0.10 & 0.97 & 0.87 & 0.89 & 0.97 & & 0.01 \\
\hline SNP11 & 0.02 & 0.15 & 0.11 & 0.17 & 0.03 & 0.24 & 0.25 & 0.29 & 0.26 & 0.13 & \\
\hline
\end{tabular}


Table 3 Probability ( $p$ ) values for the pedigree disequilibrium test (PDT) and genotypePDT (GenoPDT) in the overall dataset and the PDT conditional on APOE genotype in the family dataset

\begin{tabular}{|c|c|c|c|c|}
\hline \multirow[b]{2}{*}{ Marker } & \multicolumn{2}{|c|}{ Overall dataset } & \multicolumn{2}{|c|}{ PDT stratified by APOE genotype } \\
\hline & PDT & GenoPDT & $\begin{array}{l}\text { No APOE-4 (107 families, } \\
253 \text { DSPs) }\end{array}$ & $\begin{array}{l}\text { Carriers of APOE-4 (185 } \\
\text { families, } 477 \text { DSPs) }\end{array}$ \\
\hline SNP1 & 0.492 & 0.002 & 0.125 & 0.653 \\
\hline SNP2 & 0.099 & 0.294 & 0.205 & 0.291 \\
\hline SNP3 & 0.531 & 0.835 & 0.228 & 0.612 \\
\hline SNP4 & 0.662 & 0.567 & 0.560 & 0.502 \\
\hline SNP5 & 0.558 & 0.133 & 0.679 & 0.523 \\
\hline SNP6 & 0.011 & 0.077 & 0.827 & 0.014 \\
\hline SNP7 & 0.114 & 0.107 & 0.655 & 0.347 \\
\hline SNP8 & 0.099 & 0.065 & 0.945 & 0.614 \\
\hline SNP9 & 0.028 & 0.123 & 0.473 & 0.013 \\
\hline SNP10 & 0.160 & 0.329 & 0.366 & 0.109 \\
\hline SNP11 & 0.925 & 0.962 & 0.562 & 0.305 \\
\hline
\end{tabular}

haplotype at SNP10 and SNP11 ( $\mathrm{p}=0.004$ in APOE-4 carriers and $\mathrm{p}=0.037$ in the overall family dataset), respectively. This haplotype (with frequency of approximately 0.14) was observed more often in affected individuals than expected by chance, indicating a positive association with disease.

Though our primary focus was on detecting association, we also looked for evidence of linkage at the VR22 SNPs in our sample. Testing for linkage in the presence of heterogeneity, we obtained a maximum two point LOD (log of odds) score of 1.29 under a dominant model for SNP7 in the overall sample. Consistent with our conditional PDT analysis above, the linkage evidence increased in individuals carrying APOE-4. Specifically, for SNP7 the LOD score for the dominant model increased from 1.29 in the overall sample to 2.78 in APOE-4 carriers, for SNP6 it increased from 0.74 in the overall sample to 1.40 in APOE-4 carriers, and for SNP4 it increased from 0.35 in the overall sample to 1.42 in APOE-4 carriers.

\section{Case-control analyses}

Using the independent set of unrelated cases and controls, we did not find significant evidence of association in the overall sample. However, when cases and controls were stratified based on APOE genotype, significant $(p<0.05)$ evidence of association was found for four SNPs (table 4). SNP8 was the only marker significant in the stratum with no APOE-4 alleles (odds ratio $(\mathrm{OR})=4.67$ for carriers of allele A (95\% confidence interval (CI), 1.08 to 20.19 ), $p=0.039$ ). In the stratum with carriers of APOE-4, significant association was found for SNP3 (OR $=1.57$ ( 1.05 to 2.35) for carriers of allele $\mathrm{T} ; \mathrm{p}=0.030), \mathrm{SNP} 4 \quad(\mathrm{OR}=2.21 \quad(1.14$ to 4.32$)$ for carriers of allele A; $p=0.020)$, and SNP6 (OR $=2.12(1.01$ to
4.45) for carriers of allele $C ; p=0.047$ ). The results at SNP6 are consistent with the family based analyses, showing positive association of carriers of the $\mathrm{C}$ allele with Alzheimer's disease.

\section{Tests for genetic interactions}

Because of the differences observed when we stratified by APOE genotype, we conducted tests for interaction between SNP genotypes and APOE-4 carrier status in unrelated cases and controls. We conducted tests for interaction with APOE for the four SNPs with significant results in the stratified case-control analyses (SNP3, SNP4, SNP6, and SNP8). SNP4 and SNP8 both showed significant evidence of interaction with APOE-4 carrier status, with logistic regression adjusted for AAE and sex (table 5).

For a better understanding of the nature of the interactions, we examined the SNP genotype frequencies in the case-control sample stratified by APOE genotype. Table 5 shows the unadjusted SNP genotype frequencies from the stratified analyses reported in table 4. For SNP4, genotypes with the A allele were significantly more frequent in cases than in controls in carriers of APOE-4, but the trend was reversed in individuals without the APOE-4 allele. For SNP8, carriers of the A allele occurred significantly more often in cases than in controls in individuals without an APOE-4 allele, but again the trend was reversed in carriers of the APOE-4 allele.

The test for interaction with SNP6 was close to significant but did not reach our nominal level of $\mathrm{p}<0.05$. However, this result is still notable because SNP6 was the only marker with significant results across both family and case-control

Table 4 Probability ( $p$ ) values for case-control tests in the independent case-control dataset stratified by APOE genotype

\begin{tabular}{|c|c|c|c|c|}
\hline \multirow[b]{2}{*}{ Marker } & \multicolumn{2}{|c|}{ No APOE-4 (189 cases, 619 controls) } & \multicolumn{2}{|c|}{ Carriers of APOE-4 (395 cases, 239 controls) } \\
\hline & $11+12 \vee 22$ & $22+12 \vee 11$ & $11+12$ v 22 & $22+12 \vee 11$ \\
\hline SNP1 & 0.070 & 0.409 & 0.505 & 0.697 \\
\hline SNP2 & 0.395 & 0.988 & 0.103 & 0.580 \\
\hline SNP3 & 0.693 & 1.000 & 0.812 & 0.030 \\
\hline SNP4 & 0.563 & 0.754 & 0.880 & 0.020 \\
\hline SNP5 & 0.414 & 0.221 & 0.348 & 0.901 \\
\hline SNP6 & 0.515 & 0.348 & 0.047 & 0.707 \\
\hline SNP7 & 0.728 & 0.472 & 0.820 & 0.545 \\
\hline SNP8 & 0.039 & 0.488 & 0.322 & 0.545 \\
\hline SNP9 & 0.827 & 0.182 & 0.883 & 0.703 \\
\hline SNP10 & 0.363 & 0.478 & 0.234 & 0.505 \\
\hline SNP11 & 0.265 & 0.589 & 0.937 & 0.910 \\
\hline
\end{tabular}


Table 5 Tests for interaction with APOE-4 and stratum specific genotype frequencies in unrelated cases and controls

\begin{tabular}{|c|c|c|c|c|c|c|}
\hline \multirow[b]{2}{*}{ Marker } & \multirow{2}{*}{$\begin{array}{l}\text { Test of interaction } \\
\text { (p value) }\end{array}$} & \multirow[b]{2}{*}{ SNP genotype } & \multicolumn{2}{|c|}{ Genotype frequencies No APOE-4 } & \multicolumn{2}{|c|}{ Genotype frequencies, carriers of APOE- 4} \\
\hline & & & Cases $(n=189)$ & Controls $(n=619)$ & Cases $(n=395)$ & Controls $(n=239$ ) \\
\hline SNP3 & 0.150 & $\mathrm{GT}+\mathrm{TT}$ & 0.68 & 0.69 & 0.72 & $0.64^{*}$ \\
\hline SNP4 & 0.048 & $A A+A G$ & 0.39 & 0.43 & 0.45 & $0.32^{*}$ \\
\hline SNP6 & 0.057 & $\mathrm{CC}+\mathrm{CT}$ & 0.85 & 0.87 & 0.87 & $0.80^{*}$ \\
\hline SNP8 & 0.027 & $A A+A G$ & 0.99 & $0.95^{*}$ & 0.92 & 0.95 \\
\hline
\end{tabular}

analyses. Comparison of SNP genotype frequencies (table 5) shows that genotypes carrying the $\mathrm{C}$ allele were more frequent in cases than in controls among carriers of APOE4 , but less frequent among non-carriers. Though the trends were reversed in APOE-4 carriers and non-carriers, the test for interaction was not statistically significant. However, the trends are consistent with the frequencies observed in the family data. Among carriers of APOE-4, genotypes with the C allele were more frequent in affected siblings than in unaffected siblings (90\% in affected $v 85 \%$ in unaffected). Among siblings without APOE-4, carriers of $\mathrm{C}$ were less frequent in affected siblings than in unaffected siblings (83\% in affected $v 87 \%$ in unaffected).

\section{DISCUSSION}

This study provides the first evidence of a direct effect of the VR22 gene on risk for Alzheimer's disease. We have examined several SNPs for association with Alzheimer's disease in a large family sample and an independent sample of unrelated Alzheimer cases and controls. Though several of the SNPs showed association in either the family based or case-control analyses, the most consistent findings were with SNP6, which showed significant evidence of association in the families and in the unrelated case-control sample.

Taken individually, our results are not overwhelmingly significant and certainly would not hold up to a correction for multiple comparisons; however, the compilation of evidence from multiple independent sources lends strength to the possible role of VR22 in Alzheimer's disease. VR22 is both a strong locational and functional candidate. Our previous genomic screen in 466 Alzheimer families identified peak linkage on chromosome 10 at a marker Diosi21l $(\mathrm{MLOD}=1.41)$ lying only $1.1 \mathrm{Mb}$ from the VR22 gene $^{25}$; and others have identified linkage nearby, ${ }^{26}$ making VR22 a good locational candidate. Additionally, the role of VR22 in cell adhesion and possible interaction with presenillin $\mathrm{l}^{27}$ make it a strong functional candidate for involvement in Alzheimer's disease.

Further support is given by the consistency of our results with the previous study of the relation of VR22 to A $\beta 42$ levels. ${ }^{8}$ That study identified SNP6 as being associated with plasma A $\beta 42$ levels in two sets of Alzheimer pedigrees. We have confirmed that the same marker is associated with Alzheimer status in a large sample of families, and in addition that it shows association in an independent sample of Alzheimer cases and unrelated controls. We were, however, unable to find association with other SNPs tested by Ertekin-Taner et al. ${ }^{8}$ Specifically, their most significant SNP (SNP7) showed no evidence of association with Alzheimer's disease in any of our analyses, while SNP8, which also showing significant association with A $\beta 42$ levels, was significant only in our case-control analysis. These discrepancies could be explained by the differences in the phenotypes studied, or by the large sampling variability that would be expected considering that the previous study involved samples of 22 pedigrees or fewer.
Interestingly, our significant findings were concentrated in individuals carrying APOE-4 alleles, and in fact two of the SNPs showed significant evidence of interaction with the APOE genotype. This suggests that the effect of the VR22 SNPs is dependent on APOE status. Inspection of SNP genotype frequencies among carriers and non-carriers of APOE-4 in table 5 shows that for SNP4 and SNP6, SNP genotype frequencies were similar in cases and controls without APOE-4 and in cases with APOE-4; however, the frequency in controls carrying APOE-4 differs. This suggests a possible protective effect of the SNPs, or a polymorphism in linkage disequilibrium with them, among individuals with APOE-4. The trends for SNP8 (table 5) do not offer the same simple interpretation, but the low frequency of the GG genotype makes the results at this marker difficult to judge.

The dependence on APOE-4 is also reflected in our linkage analysis of the VR22 SNPs, in which the maximum LOD score at the SNPs was strongest when only carriers of APOE-4 were used in the analysis. These results are consistent with other linkage screens, which found the evidence of linkage in this region to be stronger in affected siblings who shared APOE-4 than in those who did not in overlapping family samples. ${ }^{2}{ }^{26}$ However, despite the higher LOD score in the APOE-4 positive group, Myers et $a l^{2}$ found that the ibd estimates in the two groups were similar, showing increased sharing. They suggested this meant that their linkage did not depend on sharing at APOE, but they provided no conclusive evidence of linkage in the APOE-4 negative subset. Still it is possible that the VR22 polymorphisms act only in individuals carrying APOE-4, while other polymorphism in VR22 or other genes act in an APOE independent fashion. Only 15\% of our multiplex family sample overlap with Myers et al, ${ }^{2}$ so genetic heterogeneity could lead to discrepancies in the results.

Other studies have implicated regions of linkage further telomeric. ${ }^{3}$ There is evidence that this region may harbour genes contributing to risk or age of onset of Alzheimer's disease. Our own study found evidence that the GSTOl gene (10q25.1) is associated with age of onset. ${ }^{5}$ This gene is more than $38 \mathrm{Mb}$ away from VR22 and shows no evidence of linkage disequilibrium with VR22 SNPs; thus it is likely that these represent distinct regions, each involved in Alzheimer's disease aetiology.

The polymorphisms that we studied are all intronic with no known function. Thus it is unlikely that they directly affect Alzheimer's disease risk. Instead it is more likely that an as yet undiscovered variant or variants lead to the observed association. The analysis of linkage disequilibrium by Ertekin-Taner et $a l^{8}$ suggests that the association does not extend beyond the boundaries of the VR22 gene. However, we cannot rule out the involvement of the nested LRRTM3 gene contained in intron 7 of the VR22 gene. The LRRTM3 gene encodes a leucine-rich repeat that tends to form the amyloid fibrils that compose Alzheimer's disease amyloid plaques. The LLRTM3 protein is a brain specific protein expressed in the hippocampus. We did find some evidence of association at SNPs within LRRTM3, though these were not our most significant findings. While it is possible that these 
results simply reflect association with VR22 polymorphisms, we found little linkage disequilibrium between LLRTM3 SNPs and SNPs in VR22 in our samples.

\section{Conclusions}

Our results, combined with previous findings, support the involvement of the VR22 gene or a nearby gene in Alzheimer's disease. As we do not have data on plasma A $\beta 42$ levels in our samples, we cannot rule out the possibility that the association merely reflects association with $\mathrm{A} \beta 42$ levels. Further biological studies are required to distinguish the effect. Our results do strongly point to the importance of taking into account APOE genotype as we try to understand the role of this gene in Alzheimer disease.

\section{ACKNOWLEDGEMENTS}

We are grateful to all of the participants and their relatives who generously participated in the study. This study was supported by grants from the National Institutes of Health: R01 AG20135, R01 NS31153, R01 AG19757, and R01 AG021547, and a Zenith award ZEN-01-2935 from the Alzheimer's Association. This study was also supported in part by a GCRC award (RR 00095) to Vanderbilt University. Some work was performed using the core facilities of the Vanderbilt Center for Human Genetics Research and the Duke Center for Human Genetics.

\section{Authors' affiliations \\ E R Martin, P G Bronson, Y-J Li, N Wall, D E Schmechel, P-T Xu, J R Gilbert, M A Pericak-Vance, Department of Medicine, Duke University Medical Center, Durham, North Carolina, USA \\ R-H Chung, Bioinformatics Research Center, North Carolina State University, Raleigh, North Carolina \\ G Small, Department of Psychiatry and Biobehavioral Sciences, UCLA, Los Angeles, California, USA}

J Bartlett, N Schnetz-Boutaud, J L Haines, Department of Molecular Physiology and Biophysics, Vanderbilt University, Nashville, Tennessee, USA

Competing interests: none declared

Correspondence to: Dr Eden R Martin, 595 La Salle St, Box 3445, Duke University Medical Center, Durham, NC 27710, USA; eden.martin@ duke.edu

Received 22 November 2004

Revised version received 21 January 2005

Accepted for publication 2 February 2005

\section{REFERENCES}

1 Pericak-Vance MA, Grubber J, Bailey LR, Hedges D, West S, Kemmerer B, Hall JL, Saunders AM, Roses AD, Small GW, Scott WK, Conneally PM, Vance JM, Haines JL. Identification of novel genes in late-onset Alzheimer disease. Exp Gerontol 2000;35:1343-52.

2 Myers A, Holmans P, Marshall H, Kwon J, Meyer D, Ramic D, Shears S, Booth J, DeVrieze FW, Crook R, Hamshere M, Abraham R, Tunstall N, Rice F, Carty S, Lillystone S, Kehoe P, Rudrasingham V, Jones L, Lovestone S, PerezTur J, Williams J, Owen MJ, Hardy J, Goate AM. Susceptibility locus for Alzheimer's disease on chromosome 10. Science 2000;290:2304-5.

3 Bertram L, Blacker D, Mullin K, Keeney D, Jones J, Basu S, Yhu S, Mclnnis MG Go RC, Vekrellis K, Selkoe DJ, Saunders AJ, Tanzi RE. Evidence for genetic linkage of Alzheimer's disease to chromosome 10q. Science 2000;290:2302-3.

4 Li YJ, Scott WK, Hedges DJ, Zhang F, Gaskell PC, Nance MA, Watts RL, Hubble JP, Koller WC, Pahwa R, Stern MB, Hiner BC, Jankovic J, Allen FA, Goetz CG, Mastaglia F, Stajich JM, Gibson RA, Middleton LT, Saunders AM Scott BL, Small GW, Nicodemus KK, Reed AD, Schmechel DE, WelshBohmer KA, Conneally PM, Roses AD, Gilbert JR, Vance JM, Haines JL, Pericak-Vance MA. Age at onset in two common neurodegenerative diseases is genetically controlled. Am J Hum Genet 2002;70:985-93.

5 Li YJ, Oliveira SA, Xu P, Martin ER, Stenger JE, Scherzer CR, Hauser MA, Scott WK, Small GW, Nance MA, Watts RL, Hubble JP, Koller WC, Pahwa R,
Stern MB, Hiner BC, Jankovic J, Goetz CG, Mastaglia F, Middleton LT, Roses AD, Saunders AM, Schmechel DE, Gullans SR, Haines JL, Gilbert JR, Vance JM, Pericak-Vance MA. Glutathione S-transferase omega-1 modifies age-at-onset of Alzheimer disease and Parkinson disease. Hum Mol Genet 2003; 12:3259-67.

6 Finckh U, van Hadeln K, Muller-Thomsen T, Alberici A, Binetti G, Hock C, Nitsch RM, Stoppe G, Reiss J, Gal A. Association of late-onset Alzheimer disease with a genotype of PLAU, the gene encoding urokinase-type plasminogen activator on chromosome 10q22.2. Neurogenetics 2003:4:213-17.

7 Prince JA, Feuk L, Gu HF, Johansson B, Gatz M, Blennow K, Brookes AJ. Genetic variation in a haplotype block spanning IDE influences Alzheimer disease. Hum Mutat 2003;22:363-71.

8 Ertekin-Taner N, Ronald J, Asahara H, Younkin L, Hella M, Jain S, Gnida E, Younkin S, Fadale D, Ohyagi Y, Singleton A, Scanlin L, De Andrade M, Petersen R, Graff-Radford N, Hutton M, Younkin S. Fine mapping of the alpha-T catenin gene to a quantitative trait locus on chromosome 10 in lateonset Alzheimer's disease pedigrees. Hum Mol Genet 2003;12:3133-43.

9 Gravina SA, Ho L, Eckman CB, Long KE, Otvos L, Younkin LH, Suzuki N, Younkin SG. Amyloid beta protein (A beta) in Alzheimer's disease brain. Biochemical and immunocytochemical analysis with antibodies specific for forms ending at $\mathrm{A}$ beta 40 or $\mathrm{A}$ beta 42(43). J Biol Chem 1995:270:7013-16.

10 Younkin SG, Ertekin-Taner N, Xin T, Baker M, Younkin LH, Hutton M, GraffRadford N. Role of elevated amyloid B protein in patients with typical late onset Alzheimer's disease [abstract]. Neurobiol Aging 2000;21(suppl 1):136.

11 Mayeux R, Tang MX, Jacobs DM, Manly J, Bell K, Merchant C, Small SA, Stern Y, Wisniewski HM, Mehta PD. Plasma amyloid beta-peptide 1-42 and incipient Alzheimer's disease. Ann Neurol 1999;46:412-16.

12 Ertekin-Taner N, Graff-Radford N, Younkin LH, Eckman C, Baker M Adamson J, Ronald J, Blangero J, Hutton M, Younkin SG. Linkage of plasma A $\beta 42$ to a quantitative locus on chromosome 10 in late-onset Alzheimer's disease pedigrees. Science 2000;290:2303-4

13 McKhann G, Drachman D, Folstein M. Clinical diagnosis of Alzheimer's disease: Report of the NINCDS-ADRDA Work Group under the auspices of the Department of Health and Human Services Task Force on Alzheimer's Disease. Neurology 1984;34:939-44

14 Oliveira SA, Scott WK, Nance MA, Watts RL, Hubble JP, Koller WC, Lyons KE, Pahwa R, Stern MB, Hiner BC, Jankovic J, Ondo WG, Allen FH, Scott BL, Goetz CG, Small GW, Mastaglia FL, Stajich JM, Zhang F, Booze MW Reaves JA, Middleton LT, Haines JL, Pericak-Vance MA, Vance JM, Martin ER. Association study of Parkin gene polymorphisms with idiopathic Parkinson disease. Arch Neurol 2003;60:975-80.

15 Saunders AM, Strittmatter WJ, Schmechel D, George-Hyslop PH, PericakVance MA, Joo SH, Rosi BL, Gusella JF, Crapper-MacLachlan DR, Alberts MJ. Association of apolipoprotein $\mathrm{E}$ allele epsilon 4 with late-onset familial and sporadic Alzheimer's disease. Neurology 1993;43:1467-72.

16 Genetic Data Analysis: Computer program for analysis of allelic data 2000.

17 Abecasis GR, Cookson WO. GOLD - graphical overview of linkage disequilibrium. Biolnformatics 2000;16:182-3.

18 Martin ER, Monks SA, Warren LL, Kaplan NL. A test for linkage and association in general pedigrees: the pedigree disequilibrium test. Am J Hum Genet 2000;67:146-54.

19 Martin ER, Bass MP, Kaplan NL. Correcting for a potential bias in the pedigree disequilibrium test. Am J Hum Gen 2001;68:1065-7.

20 Martin ER, Bass MP, Gilbert JR, Pericak-Vance MA, Hauser ER. Genotypebased association test for general pedigrees: the genotype-PDT. Genet Epidemiol 2003;25:203-13

21 Martin ER, Bass MP, Hauser ER, Kaplan NL. Accounting for linkage in familybased tests of association with missing parental genotypes. Am J Hum Genet 2003;73:1016-26.

22 Lathrop GM, Lalouel JM, Julier C, OH J. Strategies for multilocus linkage analysis in humans. Proc Natl Acad Sci USA 1984;81:3443-6.

23 Terwilliger JD, OH J. Handbook of human genetic linkage. Baltimore: Johns Hopkins University Press, 1994.

24 SAS Institute. SAS/STAT user's guide (version 8), 4th ed. Cary, NC: SAS Institute, 2000.

25 Haines JL, Bailey LR, Grubber JM, Hedges D, Hall JL, West S, Santoro L, Kemmerer B, Saunders AM, Roses AD, Small GW, Scott WK, Conneally PM, Vance JM, Pericak-Vance MA. A genomic search for Alzheimer's disease genes. In: Iqbal K, Sisodia SS, Winblad B, eds. Alzheimer's disease: advances in etiology, pathogenesis and therapeutics. London: John Wiley and Sons, 2001:33-43.

26 Kehoe $P$, Wavrant-De Vrieze F, Crook R, Wu WS, Holmans P, Fenton I, Spurlock G, Norton N, Williams H, Williams N, Lovestone S, Perez-Tur J Hutton M, Chartier-Harlin MC, Shears S, Roehl K, Booth J, Van Voorst W, Ramic D, Williams J, Goate A, Hardy J, Owen MJ. A full genome scan for late onset Alzheimer's disease. Hum Mol Genet 1999:8:237-45.

27 Zhang ZH, Hartmann H, Do VM, Abramowski D, Sturchler-Pierrat C, Staufenbiel M, Sommer B, van de Wetering M, Clevers H, Saftig P, De Strooper B, He X, Yankner BA. Destabilization of beta-catenin by mutations in presenilin-1 potentiates neuronal apoptosis. Nature 1998;395:698-702. 